\title{
The Prospects for the Use of Digital Technology "Blockchain" in the Pharmaceutical Market
}

\author{
Vladimir Plotnikov ${ }^{1, *}$, and Valentina Kuznetsova ${ }^{2}$ \\ ${ }^{1}$ Saint-Petersburg State University of Economics, 21 Sadovaya str., St. Petersburg, Russia, 191023 \\ ${ }^{2}$ Herzen University, 48 Moika emb., St. Petersburg, Russia, 191186
}

\begin{abstract}
The development of information technology in the modern economy is one of the drivers of economic growth. Digital technologies are developing at an accelerating pace. Digitalization stimulates not only economic, but also social and technological progress. The impact of digital technology in different industries is not the same. The authors of the article consider such promising modern technology as Blockchain. Its advantage is that the information is protected from unauthorized modification. This transforms the system of economic relations. The level of trust increases. Opportunistic behaviour of participants in contractual relations is blocked. As a result, economic efficiency improves. These positive effects are analyzed in the case of the pharmaceutical industry. The introduction of Blockchain technologies into pharmaceuticals allows you to track all stages of production of drugs and guarantee their quality. Blockchain technology allows you to confirm the authenticity of recipes and the drugs with the help of special digital devices. The consequence of this is a reduction in the number of counterfeit drugs on the market, as well as improving the quality of medical care for the population.
\end{abstract}

\section{Introduction}

In the late XX - early XXI centuries, another industrial revolution took place. Its main content is the rapid development of digital technologies. These technologies penetrate into all spheres of human life. They cause dramatic changes. Of course, these problems are reflected in scientific research [1, 2, 3, 4, etc.], as well as in government policies. An example of this kind is the program "Digital Economy of the Russian Federation" (approved by the decree of the Government of the Russian Federation of July 28, 2017 No 1632).

Digital technologies can change many processes of interaction between economic agents. They make this interaction cheaper, faster and more reliable. Their development will help solve many problems of the economy and society. As a result, economic and social efficiency improves. These positive effects are analyzed by the authors in the case of the pharmaceutical industry.

\footnotetext{
*Corresponding author: plotnikov_2000@mail.ru
} 


\section{The problem of providing the population with medicines}

One of the most important problems of modern Russia is to provide the country's population with modern, highly effective and high-quality medicines. This problem is not specifically Russian. According to the World Health Organization, the world's illegal drug market is $\$ 30$ billion. It is estimated that one in ten medicines in middle-income and low-income developing countries is counterfeit. People who take such medicines not only lose money, but also put their health and life at serious risk. So, according to the experts of the University of Edinburgh, around 100,000 children die every year from pneumonia. The reason for this is the use of counterfeit antibiotics.

According to official government statistics (Source: "Roszdravnadzor"), in Russia in 2016 the share of counterfeit medicines on the market was $0.0046 \%$; the share of illegally sold drugs is $0.012 \%$. These indicators are much lower than in developing countries. Nevertheless, the problem of the quality and legitimacy of the origin of drugs in Russia, according to the authors of the article, is important. This is reflected in the legislation of the Russian Federation. Federal Law No 61-FZ of 12.04.2010 "On circulation of medicines" defines the main directions for improving the system of providing the population with quality medicines and medical products:

- Creation of optimal models of pricing and procurement of effective and safe medicines.

- Development of a strategy aimed at ensuring the rational use of medicines by doctors and patients.

- Promoting the development of domestic production of pharmaceuticals.

- Ensuring control over the quality, safety and effectiveness of domestic and imported medicines.

The system of production and supply (sales) of medicines is very complex. It covers the processes: the production of medicines (the production itself includes many stages and participants, since modern drugs are a complex product), their logistics, leave in prescription and over-the-counter form in retail, deliveries to hospitals. Each link in the chain of commodity circulation of the drug from the producer to the consumer (the patient) can be controlled by a separate company or even by a number of competing and cooperating organizations.

Naturally, the activities of these pharmaceutical companies are informatized. Each of them has its own computer network, software, accounting and reporting system, electronic database, etc. Moreover, these information systems and elements, as a rule, are not connected with previous and subsequent participants of the chain of goods circulation. The exchange of information between these companies and state organizations is carried out. But the reliability and completeness of the transmitted information are not guaranteed. Information may be distorted. This creates a technical basis for violations (the production of counterfeit drugs, the importation of unregistered medicines into the country, etc.). This creates a threat to the consumer.

It is necessary to ensure control over the quality, safety and efficacy of medicines. But with the existing organization and technologies, this does not seem impossible. For example, according to the Ministry of Internal Affairs of the Russian Federation (2017), the number of falsified medicines sold through the Internet in Russia has doubled in three years. About 700 Internet sites were identified, on which prescription drugs were illegally sold. For the illegal manufacture and distribution of medicines, about 400 people were brought to justice.

Low-quality drugs can reach patients not only because of criminal activity. The precondition for this negative phenomenon is the limited possibility of introducing quality standards in production. Counterfeit medicines are used where there is an improper government regulation of the market. And it is combined with unethical business practices of wholesalers, distributors, retailers and healthcare professionals. Control is complicated by 
the fact that many counterfeit medicines are produced in one country, packed in another, and then sent to a third country for final sale and consumption.

\section{Digital drug control systems}

In Russia, as in many other countries around the world, there is a need to monitor information at all stages of developing and supplying pharmaceutical products using digital technologies. This will make it impossible to turn counterfeit medicines.

One of the first technologies of the digital economy to follow all the stages of product promotion was the management of the American trading network "Walmart". Heads of the network created a system that allows you to track information about the movement of food products from the producer to the end user. This system is built on the basis of Blokchain technology.

Blokchain is a distributed database that is not stored on a single server, but is duplicated on thousands of computers that are networked. Blokchain is a chain of blocks that any person can access. This is a distributed registry technology, the records in which can cover information about the product being created at all stages of its movement towards the consumer. In such a register, each subsequent block has information about the creation time and continues the previous block, referring to it. With this model of data storage, it is impossible to make changes to one block without changing all others.

In the classical database management systems, information is stored in disparate databases and may be subject to adjustment (including malicious intent). The main advantage of Blokchain is that the data entered once cannot be changed by anyone, they are repeatedly duplicated and stored in a distributed computer network created and maintained by all its participants. These data are always available, they cannot be faked; the technology of the distributed registry makes information resistant to hacker attacks.

Consider the situation with the production and turnover of pharmaceutical products. In the Blokchain document, if the supplier of medicines or their seller decided to make changes to the record, a new document will automatically be created, as a continuation of the main document, but already with corrections. A growing list of ordered records forms a chain of events. Each block contains a timestamp and a link to the previous block. However, it cannot be moved by changing the chronological order. This gives the effect of "transparency", allows you to organize an objective accounting. It is important to note that there is no centralized regulator here, which acts as a guarantor of information security. But, at the same time, such a central regulator (due to hacker attacks, unethical behavior, etc.) could change and move data at its own discretion, distorting them. In Blokchain such a situation is excluded.

In Russia, special attention in the information and automation of business and social processes is given to the healthcare sector as one of the priorities in the social sphere. The country provides (Federal Law of July 29, 2017 No 242 "On Amending Certain Legislative Acts of the Russian Federation on the Application of Information Technology in the Sphere of Health Care") in the medium term, the creation of Federal Information Systems for Medical and Pharmaceutical Organizations. These information systems should improve the quality and effectiveness of management by improving information support. In the opinion of the authors of the article, these information systems should use the technology of Blokchain. 


\section{Experience and problems of introducing digital technologies in pharmaceuticals}

The problem of introducing digital technologies, in particular - Blokchain, in the pharmaceutical industry is complex. When solving it, we must face the solution of a complex of organizational, technological, legal, social and economic tasks. The search for an optimal solution under these conditions is difficult to implement. In this regard, it is advisable to start with the implementation of pilot projects. On this path went to Russia.

Since April 2018, in one of the hospitals in the Novgorod region, with the support of the State Corporation "Bank for Development and Foreign Economic Affairs" and the Government of the region, a program for monitoring the circulation of medicines based on Blokchain technology has been launched [5]. During the implementation of the project, a single register of electronic prescriptions was created in the hospital. This registry is integrated with the hospital information system. The created information system is open. Patients have an authorized access to it. They can control personal medical information. The use of Blokchain allowed to protect this information from unauthorized access (hacking) and guarantee its reliability. Based on the technology of the Blokchain, information will be kept about compliance with medical standards, sources of receipt of drugs and their use. With the information system, the patient will be able to control the provision of prescribed medications to him. This excludes abuse, provides transparency in the distribution and use of medicines.

The experience gained during this pilot project will later be extended to other hospitals. Digitalization covers other subsystems of the pharmaceutical industry, not only the processes of distribution and use of drugs. At present, Russia has created prerequisites for the widespread introduction of digital technologies in pharmaceuticals as a whole. Blokchain technology can be used at all stages of drug movement from manufacturer to patient. One of the important directions of development is associated with labeling drugs with a special chip to protect against fakes. Based on the use of Blokchain technology and this chip, you can distinguish real medicine from counterfeit. For this purpose, special electronic devices will be used.

A joint pilot project (for research and production stages of operations) with the use of Blokchain was launched by Big Pharma companies - "Pfizer", "Amgen", "Sanofi" [6]. The project envisages the use of Blokchain technology to document the testing of new drugs. This will create a database of each new drug, as well as people who have expressed a desire to participate in such tests. Universal database of information storage will allow to document, save and update all data on the effectiveness of the tested drugs, their side effects. This will speed up the process of creating new drugs and bringing them to the market.

Steps are being taken for multinational cooperation in the field of using Blokchain in the fight against counterfeiting in pharmaceuticals. This problem, as we mentioned earlier, is very important. For example, in early 2018, the start-up "FarmeTrast" (London) signed an agreement with the government of Mongolia on a pilot project [7]. The project envisages the use of Blokchain technology to prevent the supply of counterfeit medicines to hospitals and pharmacies in Mongolia. From the Mongolian side, the government and the public take part in the project. The project provides assistance to the government and civil society institutions in monitoring the turnover of medicines, monitoring the supply chain of pharmaceutical products, including wholesale and retail trade enterprises.

In the future, Russia, China and other countries may be involved in international cooperation in the fight against counterfeiting of drugs. This will help solve the problem of fighting counterfeit pharmaceutical products in the market [8-10]. 


\section{The positive effects of the Blokchain technology implementation in pharmaceuticals}

- It is possible to translate all document circulation of pharmaceutical organizations into a Blokchain. This solution will increase the speed of processing information, ensure transparency of document circulation, eliminate the possibility of loss, damage or forgery of documents. These advantages are determined by the technology itself, the created block cannot be changed, it cannot be deleted.

- Blocking will ensure that information cannot be falsified. The sale of substandard or counterfeit medicines will be excluded. This is achieved through the control of all elements of the chain of production, logistics and sales of drugs.

- A single register of electronic recipes will be created. This will effectively combat the trafficking of falsified drugs. Such a violation as an illegal resale of expensive drugs purchased at the expense of budget funds in the commercial market will be eliminated. Each patient will be able to verify the validity of compliance with medical treatment standards and the number of drugs received by him.

- Savings will be achieved by not taking into account prescription drugs on paper. This account will replace the entries in the electronic register. This will greatly simplify and accelerate control over the release of prescription drugs, reduce labor and material costs.

- A national registry of medical information about patients will be created. This will make it easier, cheaper and faster to research and develop new medicines; more efficiently distribute the budgets of health insurance funds and the state budget (in terms of money allocated for health); efficiently solve other tasks in the field of health care.

- Ensure transparency of financial flows in healthcare, especially in its public sector.

- Reduce the state budget spending on quality control of medicines. These costs will decrease in absolute terms due to the use of Blockchain. Most of them will be paid by industry companies that are interested in promoting their quality products to the market, as well as in fair competition (excluding counterfeit medicines from the market).

\section{Conclusion}

Summing up the analysis, we can conclude that the use of Blockchain creates prerequisites for improving efficiency in the pharmaceutical industry and the pharmaceutical market. The state in Russia actively supports these processes. The state program "Digital Economy of the Russian Federation" emphasizes the need to introduce digital technologies. For this purpose, the state supports and finances the formation of the national information infrastructure, creates an information security system, improves regulatory and legal regulation, the formation of research competencies and technological reserves, training, etc. These common measures create a favourable environment for the introduction of digital technologies in pharmaceuticals.

Today, digital and Blockchain technologies in pharmaceuticals are implemented in the form of start-ups and pilot projects. However, in the near future, with the accumulation of experience and cheapening of technologies, increasing their availability, we expect the creation of regional, national and even global information systems. These systems will be linked to the network based on the use of distributed databases of reliable data: developers and manufacturers of medicines, distributors, pharmacies, hospitals, patients, as well as state and international organizations regulating and controlling the pharmaceutical industry the pharmaceutical market. 


\section{References}

1. A. Babkin, V. Plotnikov, Y. Vertakova. SHS Web of Conferences, 44 (2018).

2. V.I. Lutin, E.N. Desyatirikova, O.V. Kuripta, N.V. Akamsina, V.E. Mager. Proc. of the 2018 IEEE Conference of Russian Young Researchers in Electrical and Electronic Engineering, ElConRus 2018 (2018).

3. S. Johansen. A Comprehensive Literature Review on the Blockchain Technology as an Technological Enabler for Innovation. [Online]. Available: https://www.researchgate.net/profile/Stefan_Johansen2/publication/312592741_A_Co mprehensive_Literature_Review_on_the_Blockchain_Technology_as_an_Technologic al_Enabler_for_Innovation/links/5a54c2f7a6fdcc51a61a57e5/A-ComprehensiveLiterature-Review-on-the-Blockchain-Technology-as-an-Technological-Enabler-forInnovation.pdf?origin=publication_detail.

4. K. Schwab. The Fourth Industrial Revolution. World Economic Forum, Geneva, Switzerland (2016).

5. A. Levkovich. VEB launched a system for monitoring the turnover of drugs on the basis of blockchain. [Online]. Available: https://vademec.ru/news/2018/04/16/veb-zapustilmonitoring-oborota-lekarstv-na-osnove-sistemy-blokcheyna-v-novgorodskoy-oblasti.

6. A. Markov. Use of blockchain in pharmaceutics and medicine. [Online]. Available: https://miningbitcoinguide.com/technology/blokchejn-v-meditsine/

7. A. Alexander. Blokchain will help in the fight against counterfeit. [Online]. Available: https://dailyhype.ru/2018/02/19/blokcheyn-pomogaet-v-borbe-s-kontrafaktom-vfarmacevtike.html.

8. A. Bolotin, V. Bakayev, Journal of Human Sport and Exercise 12, 405-413 (2017) doi:10.14198/jhse.2017.122.17

9. B. Alexander, B. Vladislav, Journal of Physical Education and Sport 16, 910-913 (2016), doi:10.7752/jpes.2016.03143

10. B. Alexander, B. Vladislav, Journal of Physical Education and Sport 15, 362-364 (2015), doi:10.7752/jpes.2015.03054 